\title{
Building Transparent Knowledge Management Networks in the Public Sector
}

\author{
Rossella Aiello $^{1}$, Marco Bisogno ${ }^{2} \&$ Giancarlo Nota ${ }^{3}$ \\ ${ }^{1}$ Assistant Professor in Computer Science, Department of Management \& Innovation Systems, University of \\ Salerno, Italy \\ ${ }^{2}$ Associate Professor in Accounting, Department of Management \& Innovation Systems, University of Salerno, \\ Italy \\ ${ }^{3}$ Associate Professor in Computer Science, Department of Management \& Innovation Systems, University of \\ Salerno, Italy \\ Correspondence: Marco Bisogno, Department of Management \& Innovation Systems, University of Salerno, \\ Italy. E-mail: mbisogno@unisa.it
}

Received: March 28, 2018

doi:10.5539/ijbm.v13n9p50

\author{
Accepted: July 15, 2018 \\ Online Published: August 1, 2018 \\ URL: https://doi.org/10.5539/ijbm.v13n9p50
}

\begin{abstract}
This study proposes a knowledge management network framework of local governments, investigating how it can affect transparency and improve services provided to citizens. Adopting an 'action research' approach, the study provides a framework for implementing a knowledge management network, able to emphasise the role of transparency in the public sector context. The findings from its implementation show that it is now no longer possible to focus only on administrative processes or intra-organisational management, which are the central preoccupations of the new public management paradigm. Institutional theory suggests that IT innovations do not often change existing routines and organisational structures. Considering the potentiality of the network to increase transparency and provide new integrated services, our findings highlight that the main challenge is on modifying inter-organisational routines, considering citizens as components of the network. The paper combines managerial and technological perspectives on transparency and public service delivery.
\end{abstract}

Keywords: knowledge management systems, shared knowledge, service innovation, action research

\section{Introduction}

The motivation for a study of a knowledge management network in the local government (LG) context is based on the growing relevance of knowledge acquisition and creation, knowledge dissemination and knowledge utilisation (Bartocci, 2008), with the main aims being to improve transparency of public sector entities and to provide new integrated services.

Transparency has achieved increasing relevance from several perspectives, and scholars have provided different definitions (Vishwanath and Kaufmann, 2001; Florini, 2000; Hollyer et al., 2011; Bellver and Kaufmann, 2005), emphasising both its 'information component' (OECD, 2002) and its role as an accountability and constraining mechanism on public officials' behaviour (Andreula et al, 2009; Kopits and Craig, 1998). Considering the role of the ICT tools, transparency implies that 'it is not the information itself that is important but the fact that the information is potentially discoverable' (Williams, 2015) and at the disposal of the general public. Accordingly, information is supposed to be (Steccolini, 2004): a) available, reliable and qualitatively satisfying; $b$ ) understandable; $c$ ) easily accessible; and $d$ ) distributed and disseminated within a network composed of several public sector entities as well as citizens and other stakeholders. Accordingly, transparency is not an end in itself, but it plays an active role in improving the quality of services to be provided to citizens and to make providing new integrated services possible.

These last issues are well described by the complementary expressions 'knowledge society' and 'network society' (Castells, 2000a, 2000b), which mean not only focusing on the informational content, but mainly on promoting both knowledge sharing and knowledge-transfer flows (Mussari, 2003; Vătămănescu et al., 2016) through a process-based approach centred on connectivity. According to previous literature (Uzzi and Lancaster, 2003; Rathi et al., 2014), the competitiveness of organisations largely depends on their degree of connection with both 
the knowledge and the network-based pillars of the present socioeconomic dynamics. Scholars (Cardoso et al., 2012; Cegarra-Navarro et al., 2016) have also highlighted that Knowledge Management (KM) is a pivotal factor for generating value and increasing it, emphasising the role of ICTs in supporting KM practices (Martelo-Landroguez and Cegarra-Navarro, 2014; Palacios-Marqués et al., 2015; Dong et al., 2016).

As observed by Kapucu (2014), the literature concerning network governance is mainly conceptual and theoretical in nature, and only a few studies have empirically investigated such issues in the public sector context. Additionally, developing a KM culture and investigating a KM network within the public sector is particularly challenging (Amayah, 2013; Edge, 2005: 45; Mcadam and Reid, 2000) due to the following factors (Massaro et al., 2015):

- $\mathrm{KM}$ in the public sector is organisationally specific.

- Public sector organisations are facing even more competition, performance measurement, performance standards, demands for flexibility and accentuated emphasis on results and citizens' satisfactions (De Angelis, 2013, p. 1).

- Public sector entities experience great pressures for representativeness, accountability and responsiveness (Jain and Jeppesen, 2013, p. 347).

- Previous studies on KM and knowledge network in the public sector have largely focused on the higher education field; therefore, other public-sector entities, such as regional or local governments (LGs), have been understudied.

Focusing on this last point, this study aims to propose a constructive approach to the building of a Knowledge Management Network (KMN), assuming as a starting point the top-level conceptual framework proposed by Stankosky $(2005)$ as extended by Franco et al. $(2008,2010)$. Due to knowledge sharing and the integration and openness of different repositories, this study will investigate the effects of a KMN on intra- and inter-organisational routines as well as on the strategic vision of politicians and managers, pointing out both the role the KMN model can play in improving the transparency and its effect on the services provided to the citizens.

This model is characterised by a high degree of flexibility, with one of the main advantages being its easy adaptability in different contexts. From a methodological perspective, this study adopts an 'action research' approach, bringing 'together action and reflection, theory and practice, in participation with others' (Reason and Bradbury, 2006, p. 1). Findings from our study show how challenging it is for politicians and managers to enlarge their strategic view, focusing not only on the positive effect of a KMN on internal processes (improving their efficiency), but especially on inter-organisational routines, which means taking care of effectiveness of services provided to the citizens.

The remainder of the paper is structured as follows. Section 2 will provide a scientific background for the study, illustrating the main issues of the open data philosophy and the conceptual framework to which the proposed model refers. Section 3 will develop the KMN framework, while section 4 will present the research methodology, also illustrating the implementation of the model in the LG context. Section 5 will discuss the results while section 6 will conclude, also pointing out future developments of the research.

\section{Open data, Open Government and Transparency: A Conceptual Framework for Knowledge Network}

In the public sector context, open data can be considered as an integral part of the broader concept of open government, which provides the openness and transparency of public sector entities. It allows both the active participation of citizens and public control over the activities carried out by a public administration (PA; Cuadrado-Ballesteros et al., 2016; Guillamón-López et al., 2011) by means of new technologies. Moreover, the publication of data held by a PA aims to prevent corruption, promote integrity and ensure awareness of the services provided to citizens.

PAs are required to rethink their operational schemes and consolidated decision-making processes, in particular from the point of view of finding ways and tools to improve the relationships with citizens (Mercado-Lara and Gil-Garcia, 2014), emphasising communication and collaboration with local communities.

Several studies have investigated these issues (Hausenblas, 2009; Bertot et al., 2010; McDermott, 2010; Napoli and Karaganis, 2010). However, Janssen et al. (2012) have highlighted that benefits of open data should not be taken for granted; therefore, they suggest going beyond conceptual ideas in order to consider empirically the barriers and myths of the open data philosophy.

Accordingly, on one hand, the opening of data leads to a more transparent, interactive and accountable 
government: to reach openness (Note 1), it is appropriate to encourage the interoperability between different open data repositories, providing the ability to combine datasets together to develop new and better services. This can increase the level of community cohesion and the sense of trust within the institutions (Ducci, 2015): a lack of transparency diminishes public trust, so they are intrinsically linked (HM Government, 2012).

On the other hand, the main challenge is that open data has no value in itself: only its use leads to value (Janssen et al., 2012). The implementation of a network where there is knowledge sharing between all the involved actors, including citizens, could support the reuse of information, facilitating the production of new services (Kassen, 2017).

Furthermore, open data requires a qualitatively new level of information support for digital interactions between different PAs and with their citizens (Lipuntsov, 2014). As a result, an increasing number of KMNs, in which participants share goals and interact with each other, exchanging data, documents and knowledge, can be observed.

The model supporting these interactions has to take into account that:

- open data producers have to cope with legal and technical requirements concerning the transparency of data, documents and knowledge, and

- open data users require easy access to new technologies, at the same time sharing information with other network participants.

Accordingly, a conceptual framework is required. Our starting point is the top-level conceptual framework for KM (fig. 1a) proposed by Stankosky (2005), which is based on four pillars:

- Leadership develops business and operational strategies, providing the policies, priorities and incentives needed to guide KM activities.

- Organisation deals with the operational aspects of functions, processes, control measures, process improvement and business process reengineering. This pillar must provide principles and techniques for enabling and optimizing the knowledge flow between these operational aspects.

- Technology enables and provides all the infrastructures and tools to support KM within the organisation.

- Learning concerns the organisational behaviour and social engineering to define principles and practices to ensure that individuals cooperate and share knowledge. Successful KM frameworks promote organisational environments that integrate learning into all segments of the organisation's domain while encouraging collaboration and innovation.
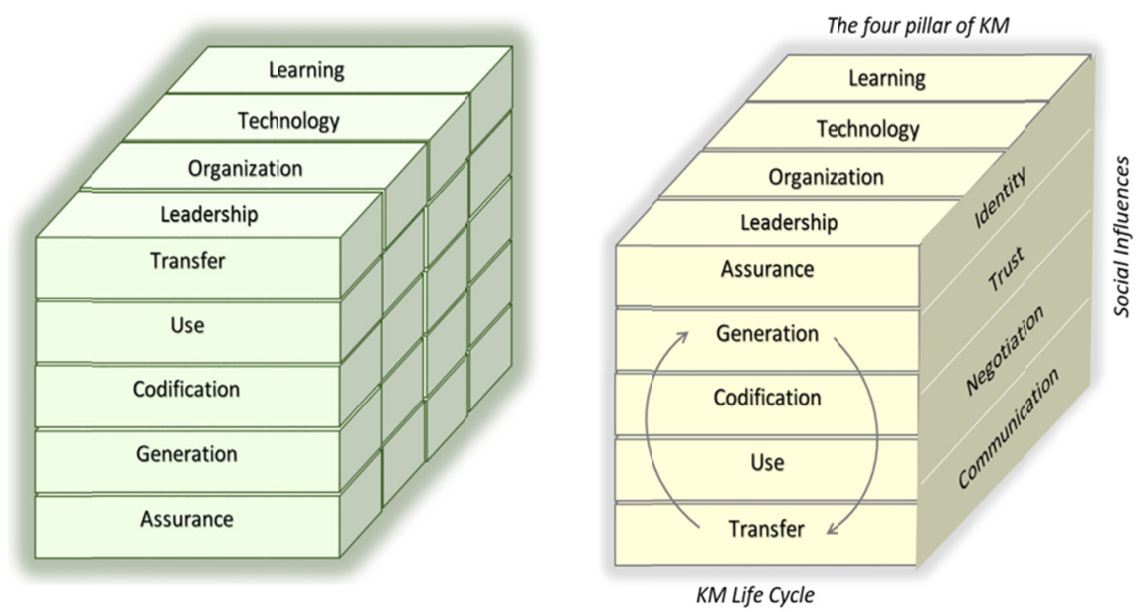

a) Top-level conceptual framework (Stankosky, 2005) b) The Local Knowledge Manager Framework

Figure 1. The structure of nodes in a KM Network

These four pillars assure the practicality of the KM life cycles, usually expressed as activities of generation, codification, use and transfer (fig. 1a). Franco et al. (2008, 2010) have extended this top-level conceptual framework by introducing aspects of identity, negotiation, trust and communication that characterise the 'social 
influence' dimension (fig. 1b). Identity is linked to one's commitments, values and goals; therefore, it is fluid, changing with the organisation's changing values and agendas. Within a KMN of PAs, the identity has to be defined for each entity belonging to the network at a meta-organisational level.

Trust is essential in supporting interconnections between organisations belonging to a network, in particular for knowledge sharing: teamwork collaboration in virtual environments requires trust (as well as collaboration and legitimacy; Dawes et al., 2009), since new ICTs may create risks and challenges (Soto-Acosta and Cegarra-Navarro, 2016). Accordingly, trust should be considered as a relevant aspect, in order to ensure that the involved PAs do not misuse the shared knowledge (e.g., by taking advantage of confidential information), and to persuade them that the network as a whole is a source of reliable information, facilitating its reuse.

Negotiation between different organisations is considered essential to perform any knowledge sharing activity inside a network (Bolisani et al., 2006). It is performed at several levels and in different circumstances. Firstly, a negotiation occurs between a PA and its citizens who wish to gain access to open data and information; secondly, there is a negotiation between an existing network and a PA that aspires to join it. Furthermore, a negotiation may be necessary to certify the object (content) of the shared knowledge. An example of this kind of negotiation is the interaction between employees and their manager shown in figure 5, concerning the process of generating and publishing a document.

The last aspect, interconnected with the previous ones, is communication. Information that is relevant in a network of PAs should be provided promptly and frequently. Communication validates the technology that is useful for enhancing social aspects (identity, trust and negotiation) as well as cooperation and collaboration within a network.

Building on this model, this study further develops the KMN framework, considering the problem of open data and transparent management of knowledge in a distributed network. The aim is to investigate its effect on intraand inter-organisational routines, highlighting the influence on transparency and public service delivery.

From a theoretical perspective, different approaches have been adopted to investigate this kind of issue (Dawes, 2013):

- resource dependence theory, which focuses on the organisation's critical resources, highlighting the relevance of gaining some forms of control over external resource providers, increasing the dependence of others;

- stakeholder theory, which considers an organisation as the hub of a set of stakeholder relationships, built to coordinate different interests or reduce environmental uncertainty;

- organisational learning theory, which stresses the ability of an organisation to recognize, absorb and apply new knowledge; and

- institutional theory, which investigates how institutional pressures for legitimacy and acceptance stimulate organisations to conform to prevailing social norms, especially imitating organisations having a well-established legitimacy and reputation.

This last approach is particularly useful in our case, considering the strong pressure on PAs to embrace the open data philosophy; however, institutional theory - more precisely, the new institutional sociology theory (NIS) (Scott, 1992; Scott and Meyer, 1992; Di Maggio and Powell, 1983) — could imply the risk of considering a PA as a 'black box', making difficult the analysis of the effects of open data on intra- and inter-organisational routines. Therefore, according to Scapens and Varoutsa (2010), this study combines NIS with the old institutional economics approach (Burns \& Scapens, 2000) to consider better how open data can modify and transform existing structures. This would make possible an assessment of the positive effects of open data on both transparency and the effectiveness of services provided to citizens, helping PAs to remove barriers to open data (Janssen et al., 2012). Therefore, considering the intrinsic processual and systemic nature of the public service delivery processes, a public service-dominant approach to ICT issues would improve engagements with citizens and, more broadly, communications with communities (Osborn et al., 2012; Osborn et al., 2014; Tat-Kei Ho, 2002).

\section{Building a Knowledge Network of PAs}

The framework described in the previous section is now extended and specialized for use in a context of PAs.

Figure 2 shows the KMN, composed of several elements:

1. Local Transparent Knowledge Managers (LTKM), who represent PAs participating in the network (e.g. the nodes of the KMN); they are the keepers of open knowledge to be shared with other participants. The 
framework shown by figure $1 \mathrm{~b}$ qualifies this component. Transparency emerges from the union of processes (that define the KM life cycle) and open data contained in the Knowledge Repository.

2. Knowledge Stakeholders are usually citizens or other organisations (e.g. local administrations, foundations, the central government, suppliers, consultants etc.) which desire to interact with the network in order to acquire or transfer open data.

3. Knowledge Repository is the virtual place where the open data repository of each node is collected. Indeed, every PA in the network owns a piece of tacit or explicit knowledge and is encouraged to consume/produce it from/to a transparent repository when it is perceived as a centralized knowledge base, even if it is truly distributed in many virtual and physical places. Open data may be collected from different local repositories and reused (by selection, merging and so on), creating other new virtual repositories. The knowledge repository for a network of PAs is, on one hand, the personalised infrastructure of knowledge communication and storing (e.g. chat, Wiki, blogs, k-bases, reputation building software, social networking software, security access software, etc.) which allows consuming/producing open knowledge. On the other hand, the knowledge repository enables PAs' actions to be known to citizens, improving transparency and achieving accountability.

4. Community Supervisor: apart from the typical functions assigned to each node, the Supervisor is capable of developing a new infrastructure, assuming the leadership in the managing of the network, stating its identity and defining the four pillars of the KMN framework.

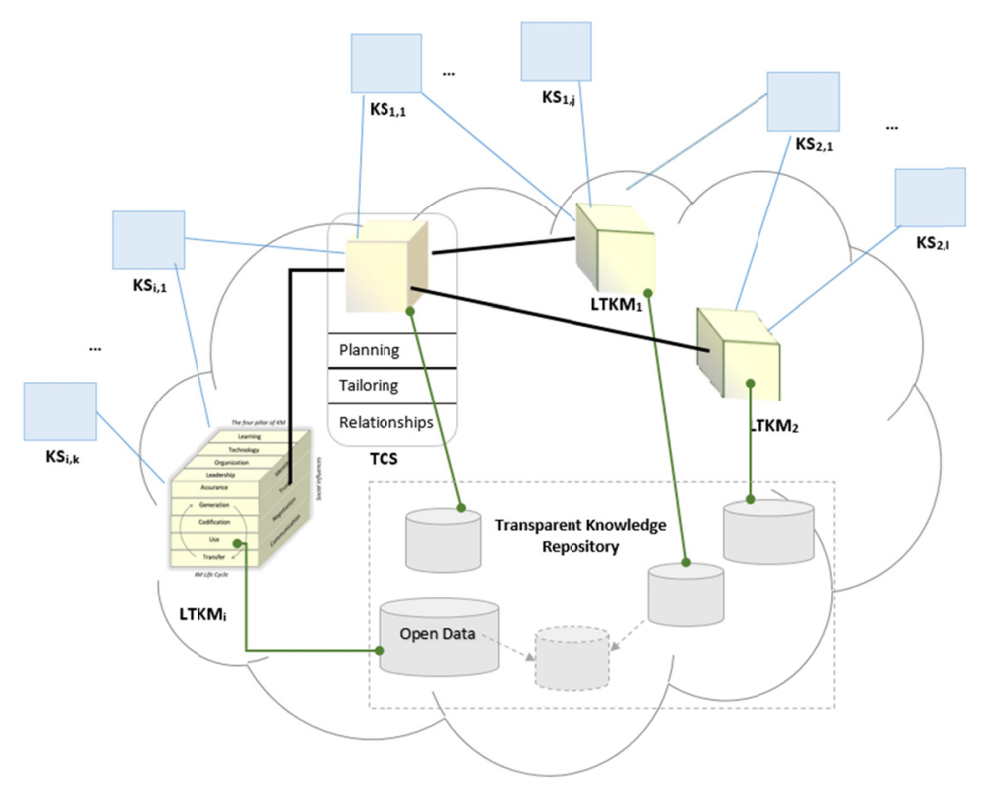

Figure 2. The meta-model for a KMN of Pas

The main phases for the implementation of a KMN, based on the proposed framework, are:

1. Planning, which means defining the four pillars (leadership, organisation, technology and learning) at the meta-level, including the social structure, the communication infrastructure and the identification of transfer protocols.

2. Tailoring, which focuses on the choice of the application domain and the models for the knowledge representation, producing the first artefacts to be shared and disseminated.

3. Relationships, which is dedicated to the identification of participants, negotiations and trust relationships, so as to define the rules that allow the node to consume/produce knowledge from/to the virtual repository.

4. Use. Each node shares its knowledge with other participants. Knowledge stakeholders receive from the virtual repository available knowledge according to the transmission rules and modalities (e.g. on demand, planned transfer, asynchronous communication, announcements, notifications, etc.) or try to exercise positive influences at the level of a single participant or on the structure and organisation of the whole KMN. 


\section{An Application of the KMN Framework to a Network of Italian Local Governments}

\subsection{Methodology}

In this study, the KMN framework has been implemented in the LG context, focusing on a network of Italian LGs created for the realisation of a project named Kalimera Project (Note 2). Kalimera involved 27 LGs of the Campania region in the south of Italy, whose community supervisor is the municipality of Giungano.

The project consists of technological and organisational innovations aiming at improving transparency, interoperability and cooperation among all the involved LGs, connecting their information systems to provide citizens with new integrated services. Moreover, the project aims to guarantee the total accessibility of the information held by the PAs, promoting a widespread control on the part of the citizens, thus improving accountability.

In order to investigate the effects of the implementation of the KMN on both intra- and inter-organisational routines, the perspective of a single node of the network (the municipality of Brusciano; see section 4.2) is firstly assumed as a starting point, then extending the analysis progressively to the network as a whole (section 4.3). In doing so, the requirements stated by the Italian regulatory framework, concerning the struggle against corruption and the improvement of transparency of PAs (Law 190/2012 and Decree 33/2013, respectively), are taken into account.

Even though the case study focuses on the Italian context, we would claim that it is of interest to the international arena since it complies with wider regulatory frameworks adopted in other contexts. Indeed, similar initiatives have been implemented in many other countries. For instance, several EU countries have adopted e-government initiatives (Del Sordo et al., 2015; EU, 2015), in accordance with the Regulation (EC) no. 1049/2001, concerning public access to documents, which aims to achieve both direct and indirect benefits of open data philosophy (e.g. new services, increased efficiency and quality in public services, time-saving for users of open data applications, and knowledge economy growth). More generally, Freedom of Information Acts have been applied in many countries to guarantee public access to information held by public authorities in two ways: $i$ ) public authorities are required to publish specific information regarding their activities; ii) citizens (and other stakeholders) are entitled to request information from public authorities.

From a methodological perspective, this study adopts an 'action research' approach (also called 'interventionist research'), which means that 'the researcher is an active participant in the process being researched' (Ryan et al., 2002 , p. 152). This approach mainly aims to solve current practical problems while at the same time expanding scientific knowledge (Demartini \& Paoloni, 2013). In this way, the interventionist researcher collaborates with the organisation in developing actual solutions to problems (Parker, 2004), providing benefits both for practitioners, who obtain the assistance and knowledge of academics, and for researchers, who can develop insights into the implementation of management innovations in organisations. Accordingly, this methodology asks for a clear specification of the tasks of both parties (Dumay, 2010). To elaborate from the single-node perspective:

1. The research team has undertaken the following tasks:

- conducted interviews with key stakeholders (manager responsible for transparency, managers of other organisational units, a sample of employees) and organised interview transcripts;

- analysed and reported findings of interviews;

- prepared material for the meetings, where a demo of the KMN framework is illustrated;

- collected comments and feedback from the participants;

- illustrated a revised demo; and

- implemented the model, also guaranteeing assistance.

2. The municipality of Brusciano has undertaken the following tasks:

- scheduled the face-to-face interviews with stakeholders and the meetings;

- distributed material for the meetings; and

- coordinated the availability of the key stakeholders and the researchers to discuss findings from the demo.

Through these tasks, the researchers were able to uncover both managerial and technological issues arising from the implementation of the KMN in an LG domain. In doing so, a critical perspective has been used, by distinguishing between the method adopted in the actual research project and the methodology employed in 
analysing interventionist research. This critical perspective, which means assessing positive and negative qualities of the 'action research' approach (Dumay, 2009), has been guided by three tasks: insight, critique and transformative redefinitions (Alvesson \& Deetz, 2000, pp. 17-20).

Insight means investigating and understanding how the implemented KMN can affect the key actors, their routines and the organisations to which they belong. Critique means avoiding taking for granted that this network would provide only benefits, so researchers are supposed to unveil also potential disadvantages (Janssen et al., 2012). Transformative redefinitions mean supporting managers to develop a critical knowledge and a practical understanding to enable changes and improvement of skills for new ways of operating.

\subsection{Focus on a Single Node}

The municipality of Brusciano is one of the Italian LGs that joined the Kalimera network. Brusciano has about 16,000 inhabitants and is located in the metropolitan area of Naples, in the south of Italy.

The first application implemented for Brusciano municipality has been an ICT system, based on a document management system (DMS), for the publication of documents of public interest on the institutional website. The second application, which integrates the first one, concerns the implementation of a whistleblowing system (Bisogno et al., 2016). This integrated system, which satisfies the requirements stated by the above-mentioned Italian regulatory framework concerning the struggle against corruption and the improvement of transparency of PAs, complies with the framework shown in figure $1 \mathrm{~b}$. It was illustrated to managers and employees during several meetings that were held to identify their roles and to assign tasks according to the model characteristics as described in Table 1.

Table 1. Mapping model characteristics on organisational roles

\begin{tabular}{|c|c|c|}
\hline Pillars of KM & KM Lifecycle & Social Influences \\
\hline $\begin{array}{l}\text { Responsible for Transparency Leadership/Technology } \\
\text { (RT) }\end{array}$ & Use/Assurance/Transfer & Identity, Trust, Negotiation \\
\hline $\begin{array}{l}\text { Five managers responsible for Organisation } \\
\text { several organisational units } \\
\text { (OU) }\end{array}$ & Generation/Transfer & Identity \\
\hline OU administrative staff & Generation/Codification & Identity \\
\hline $\begin{array}{l}\text { Citizens and external } \\
\text { stakeholders }\end{array}$ & Use & Identity, Trust, Negotiation \\
\hline
\end{tabular}

Two processes necessary for the implementation of the integrated system have been formalized using the BPMN (Business Process Model and Notation). Figure 3 shows the process of selection and publishing of the documents in the Knowledge Repository. The diagram contains the activities carried out by the three participating roles: OU Member, Manager and RT. It shows the dynamics of how the 'generation', 'codification' and 'transfer' phases take place using a BPMN model that drives the workflow execution of the process of generation and publishing within the DMS. 


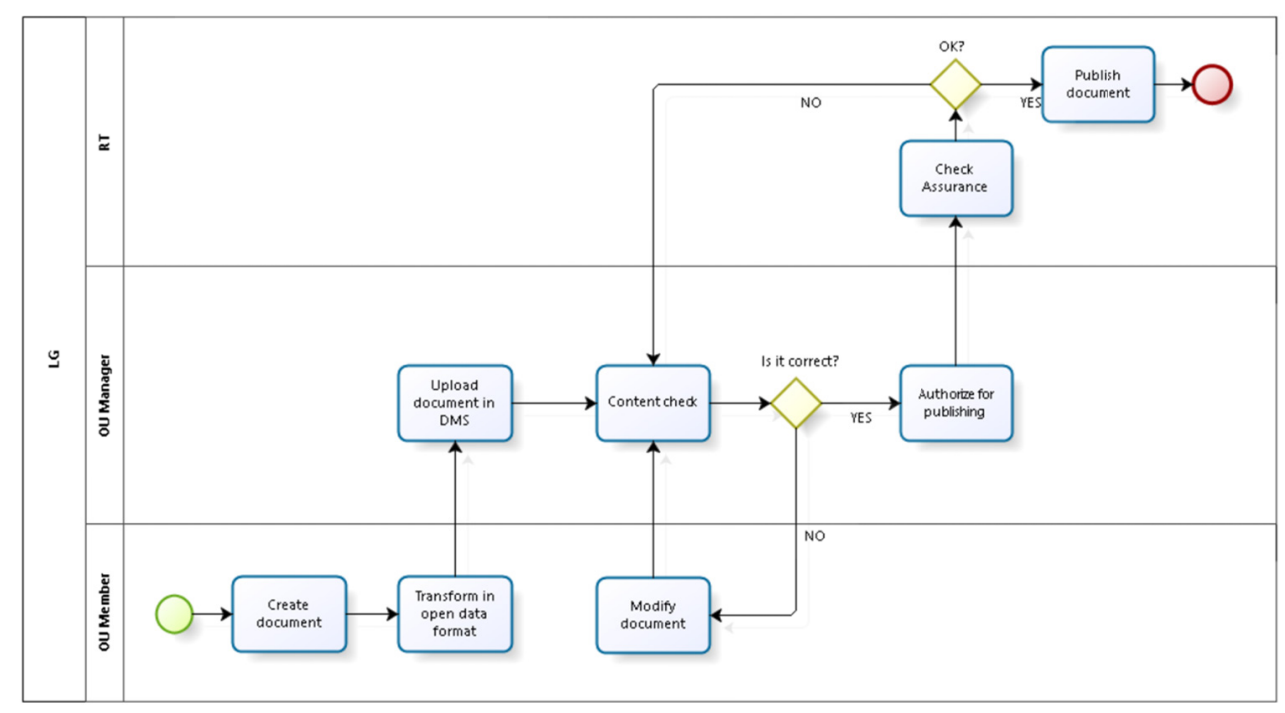

Figure 3. The process of generation and publishing of the document in the DMS

Figure 4 illustrates the process of 'civic access', according to which PAs have to disclose the documents, information or data, at the same time guaranteeing stakeholders the right to request them. This request is free and has to be sent to the RT who is obliged to satisfy it within 30 days. After the document request submission, the citizen awaits one of two possible events:

1) the notification of publishing, in which case the required document can be downloaded; or

2) the expiration of 30 days from the document request submission. In this case, an escalation sub-process can be pursued to involve another responsible party of higher degree with respect to the RT, with the aim of starting the internal process that provides service to the civic access request.

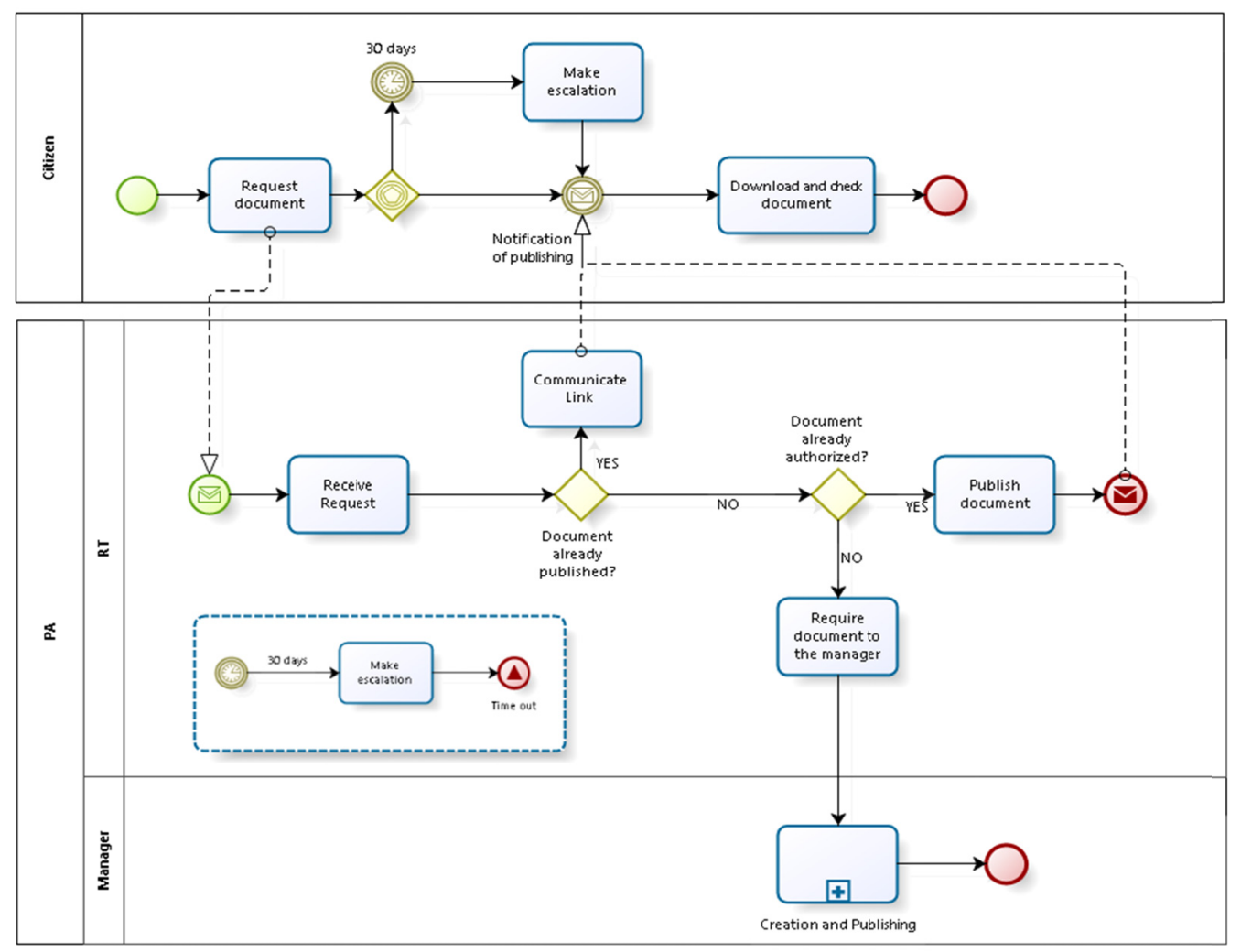

Figure 4. The process of Civic Access 
As shown in the 'social influences' column in Table 1, managing the identity is pervasive and is a prerequisite for negotiation and trust. For instance, the identification is necessary when a citizen requires the publication of a document in the public repository of Brusciano (figure 5b); furthermore, the RT must be widely identifiable so that a relationship between a citizen and the RT can be established in order to communicate. In more general terms, using the identity concept, among other things, would mean:

- discriminating between internal (e.g. employees) and external participants (e.g. citizenis) to the KMN;

- activating on-demand services;

- establishing access rights to the resources managed by the network; and

- enabling monitoring and control procedures to apply the security policies.

The identification also contributes to increasing the citizen's trust in the LG, which is considered as a source of reliable information (Franco et al., 2008, 2010). When specific interactions between two or more (identified) actors occur, negotiation is often required; for instance, the RT makes a negotiation with the OU Manager (see figure 3) to 'certify' the contents of a document to publish. In the same way, when a citizen exercises the right to access a public document, a negotiation with the RT occurs when the request needs to be specified with more details.

The services supported by the two processes previously described are accessible through the Brusciano's institutional website through interactions like those represented in figure 5. The first interaction (figure 5a) represents the public area of the DMS that allows anyone to consult and download the published documents; the second one (figure $5 \mathrm{~b}$ ) represents the form that a citizen can compile and send to demand access to a missing document in the DMS.

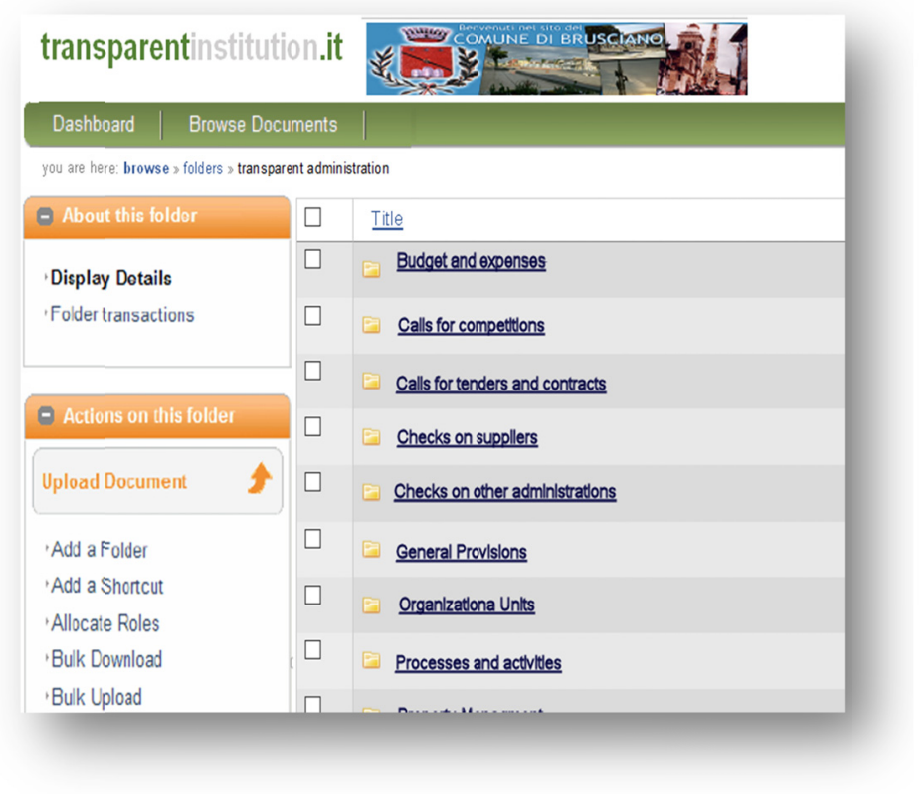

(a) The public document repository for the municipality of Brusciano

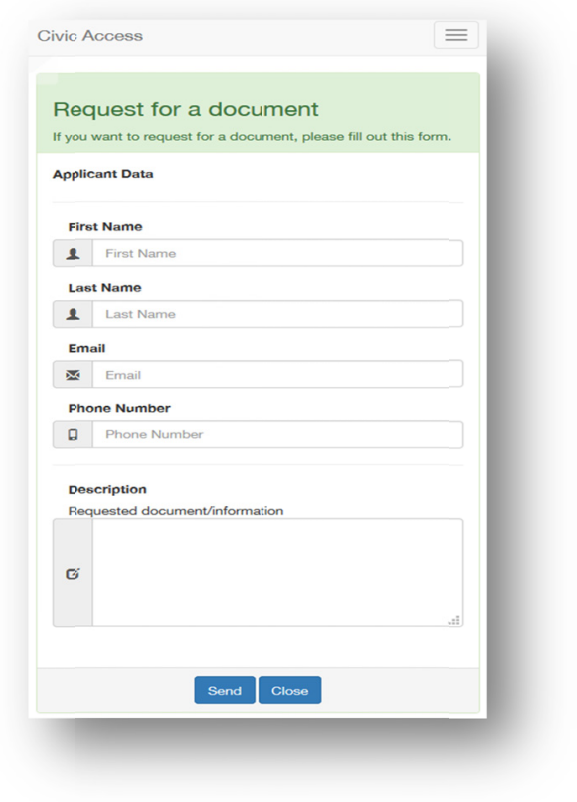

(b) The "civic access" form

Figure 5. The front office interactions for the civic access to a public document repository

The identification problem so far discussed takes into consideration people and organisations affecting a single network node. Even in this restricted scenario, if we consider technological issues, the identification is wider as it involves the identification of computers, servers, and network devices as well as the identification of software applications that run on these devices. Fortunately, the software identification management platforms already available on the market facilitate identification even in a complex network scenario such as those discussed in the next section. 


\subsection{Focus on the KMN of PAs}

Focusing on the whole Kalimera network means taking into consideration all the interactions between all the involved LGs (coordinated by the leader of the project, the LG of Giungano) as well as other external nodes. This would make clear a wider range of benefits that can be achieved by organising several LGs into a network, such as:

a) integrated services, based on the cooperation of processes active into two or more nodes;

b) new services that can arise from access to open data and common repositories;

c) reuse of common resources such as best-in-class processes, open source software, and shared knowledge objects; and

d) higher level of open government.

Apart from the benefits mentioned above, according to the new institutional sociology theory lens, several motivations can support the creation of a new network of LGs, such as a prescriptive norm, the opportunity of financial resources from a national government or the pressure that citizens exercise on their LG to provide integrated services.

Focusing on the structure of the Kalimera network, the three dimensions reported in figure $1 \mathrm{~b}$ at the network level are elucidated here:

\section{The Four Pillars of KM}

- Leadership. During the concept phase, the municipality of Giungano assumed the leadership. At the political level, a committee composed of the involved mayors shared goals and resources for the project implementation. At the managerial level, during the network creation phase, the leadership has been assumed by a manager of Giungano to drive a committee of managers for the network implementation steps.

- Organisation. The committee of managers identified $a$ ) structures and processes for the sharing of knowledge artefact, and $b$ ) a set of new services that the network has to provide to citizens.

- Technology, which concerns the hardware and software infrastructures that enable the provision of ICT services, available only when the whole network is implemented and is in operation.

- Learning. Appropriate learning paths have been realised to increase the empowerment of both the nodes and the network as a whole. Awareness of available resources and processes finalised to the provision of new integrated services has enabled the achievement of the Kalimera project's goals.

2. The KM Lifecycle

- This dimension concerns the necessary steps required for the KM at the network level, coordinated by the Community Supervisor, adopting the same steps put in place by a single node. Each node keeps its own private data and shares with other nodes the data required to enact the cross-functional processes needed to support integrated services.

3. Social Influence

- Examples of the social influence aspects, applied to the whole network, are: the identification of each node in the network, the negotiation between two nodes when one of them requires private data from the other and the trust that a certain demand from a node to the Community Supervisor will be satisfied within a given interval of time.

Bearing in mind the meta-model discussed in section 3, the Community Supervisor assumes a crucial role within the network. Indeed, it is in charge of three out of the four phases for the implementation of a KMN, namely: planning, tailoring and relationship:

- Planning. Once having concluded the decisional process aimed at the creation of a new network, the project leader devoted the attention to the steps necessary to build the network structure of Kalimera (leadership, organisation, technology and learning plans). The project leader, together with the committee of managers, planned the social structure and the technology necessary for the communication among all the stakeholders. The set of new services for the users of the Kalimera network were also identified.

- Tailoring. The reference KMN meta-model has been instantiated to implement the services recalled in section 4.1. The definition of inter-functional processes, the knowledge artefact to share and disseminate also in terms of open data and the implementation of the underlying ICT structure have been considered in this phase. 
- Relationships. The study of a network as a whole implies the analysis of the relationship between actors that comprises the network, taking into consideration the specific characteristics of the relationship among politicians, managers and citizens, as well as the involved organisational routines. In the context of Kalimera, according to the KMN meta-model, the identification of participants, negotiations, trust and relationships, together with the rules that allow the network to consume/produce knowledge from/to the virtual repository, made the realisation of network services possible.

The phases of planning, tailoring and relationships aim at providing the network structure. During the use phase, the dynamic aspects of the KMN emerged with different facets. For instance, the network has been used for the dissemination of a software application built by a node that wishes to make it available to other nodes. In this case, the network has been used for internal purposes. However, the mail goal of the Kalimera project is the provision of network services to citizens. In figure $6 \mathrm{a}$, a mobile application that reports an emergency, a potential source of fire ignition, is shown; figure $6 \mathrm{~b}$ illustrates the report collected and organised in a section of the Kalimera portal that represents all the reports coming from the local databases managed by the nodes. This is an example of a software application that supports the participation of citizens in the activities that the network devotes to the safeguarding of the territory and exemplifies how a higher level of open government can be reached within a KMN. Other software applications developed in the Kalimera project have been possible, leveraging on the concepts of open data and shared knowledge repository. For instance, a single-window application allows the interaction of an LG and a citizen who is applying for a building permit. The service provided by the single window starts a complex process that involves several PAs. This complexity is hidden and the citizen perceives an easy-to-use, high-quality service; therefore, the collaboration between different nodes of the network allows for providing several services, which each single node separately could not provide.
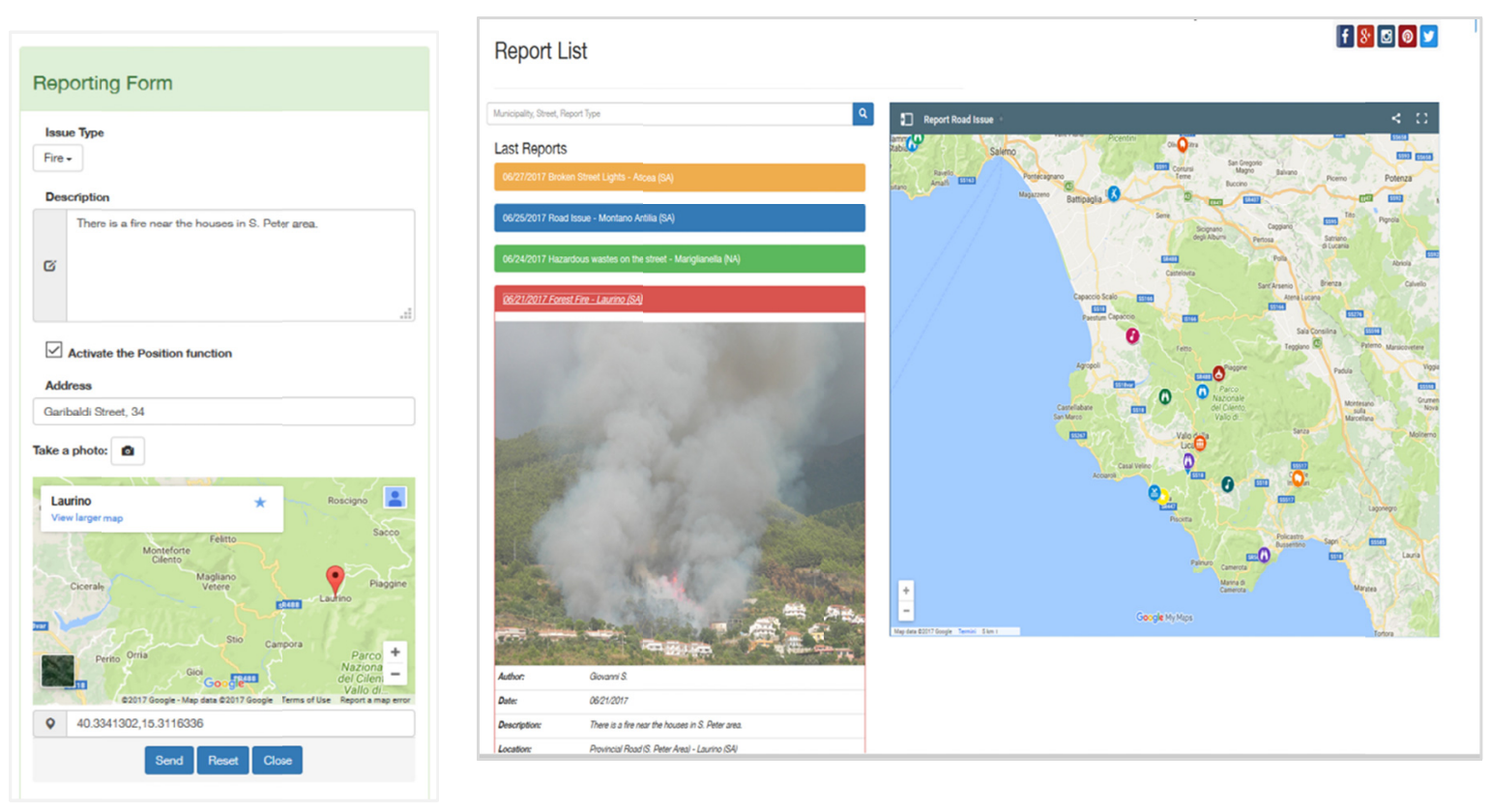

(a) Signalling of a danger with the (b) The public portal for the access to the incident D'B mobile app

Figure 6. An alarm reporting system

\section{Discussions}

The discussion of findings emerging from the investigated network will be organised by considering the three tasks of the interventionist research mentioned above: insights, critique and transformative redefinitions.

Insights

During the first phase of planning the model, all its potentialities were illustrated, as shown in Table 2.

Table 2. Meetings and interviews with managers and employees of Brusciano 


\begin{tabular}{|c|c|c|}
\hline Roles & Topics & Phase \\
\hline \multirow[t]{3}{*}{ Responsible for Transparency } & Advantages of sharing data in the network. & Planning \\
\hline & Demonstration of the model. & \\
\hline & Open data and open knowledge classification. & Tailoring \\
\hline \multirow{3}{*}{$\begin{array}{l}\text { Five managers responsible } \\
\text { several OUs }\end{array}$} & for Procedures and rules concerning data publishing and civic access. & Tailoring \\
\hline & Identification of people and roles. & Relationships \\
\hline & Introduction of a DMS as centralized data repository. & Use \\
\hline Seven employees & Open data definition and open data formats & Use \\
\hline
\end{tabular}

Brusciano's managers were aware of the capability of the model in supporting any sharing and transfer of knowledge between the LG and its citizens, as well as all other actors of the network. They perceived that the model would be able to improve citizens' care, guaranteeing more transparent behaviour. The BPMN diagrams (figures 3 and 4) provided a clear picture of how Brusciano could organise its processes to raise its communication capability within the network and towards the general public. However, managers are largely conscious that a complete implementation of the model would strongly affect (intra- and inter-) organisational routines. As a matter of fact, change processes in the institutional realm occur over long periods of time (Burns and Scapens, 2000): the implementation of a new KMN challenges existing meanings and values and contradicts existing routines, which are drawn on taken-for-granted assumptions and comprise the prevailing institutional principles. In other words, embracing the open data philosophy and improving transparency are more than mere compliance with criteria defined by a law.

As pointed out by Jönsson and Lukka (2006), interventionist researchers have to examine the different views and possibilities in order to develop interventions. In our case, managers and politicians of the LGs involved in the Kalimera project had different positions and experiences. This means that the research team attempted to find common themes around which they progressively built a shared view, experimenting step by step the technological and managerial innovations due to the KMN and the consequent effects on inter-organisational routines.

\section{Critique}

The implementation of the model benefitted from the demo and the consequent feedback and comments received by the participants during the meetings. Even though implementing such a model would go beyond mere compliance with legal requirements (institutional isomorphism; Di Maggio and Powell, 1991), in the current phase, the implemented KMN model at a single-node level is mainly used as a 'one-way' system (Ducci, 2015), with the main aim being to improve the efficiency of the internal processes. Furthermore, even if the information is largely shared between the open data producer (each node) and some open data users (mainly its citizens), the potentialities of the model, as exemplified by figure 6 , are not fully used.

Actually, while there is a wide reuse of information within each single node, there is only a partial reuse of information at the inter-organisational level. However, reuse is a fundamental element of a KMN, since it would improve the quality of services currently provided to the citizens, at the same time making the creation of new services possible, thanks to the open access any interested parties have to a common knowledge repository.

It is worth recalling that trust asks for a wide collaboration, especially at the inter-organisational level, in order to manage KMN successfully (Soto-Acosta and Cegarra-Navarro, 2016). Collaboration, in turn, implies that citizens (and the general public) are confident that the LG and the network to which it belongs are a source of reliable information and that they do not misuse the shared knowledge. In other words, a lack of trust and collaboration could impede the reuse of information.

\section{Transformative Redefinitions}

The primary objective of interventionist research is to solve, rather than merely explore, specific problems and to improve organisational processes and routines (Dumay, 2010; Jakkula et al., 2006, p. 2). Therefore, according to the point of view of the managers, a possible explanation of the problems mentioned above would reside in the technical and organisational difficulties in producing and sharing data, information and knowledge not only as an individual subject but also as a network of organisations. This means that the meta-network model can be considered as a final step of a composite process of changes a PA is expected to perform, in order to embrace the open data philosophy entirely. Managers are conscious that, at an inter-organisational level, the necessary processes of change are more complicated since they involve several external actors.

This would mean that each node, in this current phase, is forcedly focused on the efficiency of the internal 
processes. However, the research team progressively supported managers to go beyond the current step, which should be considered only as a preliminary one. As a result, the model is going to extend the strategic vision of managers and politicians, who perceive the potentiality of the network. In this way, according to Margetts (2006), so-called 'digital governance' can lead to real citizen engagement with public service delivery, with the crucial point being the new challenges originated by it, especially trust within a service-dominant context.

The next critical and important step Kalimera components would perform is to look at the effectiveness, also evaluating the implications for the organisational culture of these innovations from a user's perspective (Osborn et al., 2012, 2014).

From a network point of view, the results emerging from the study suggest combining a top-down approach with a bottom-up approach. The former is a necessary step, consisting of the definition (mainly by a law) of the legal requisites of an ICT model based on the open data philosophy. The latter will complete the former, taking into consideration the specific organisational routines of each PA (Burns and Scapens, 2000), in order to suggest implicitly how to enhance the multiple features of transparency, improving both the efficiency and the effectiveness of the services provided to the citizens.

In this vein, the results emerging from the study are consistent with the lines of argument presented by Osborne (2009) and Osborne et al. (2012): it is now no longer possible to continue focusing only on administrative processes or intra-organisational management, which are the central preoccupations of the new public management philosophy. It is time to integrate these approaches with a broader paradigm, which underlines both the relevance of inter-organisational relationships and the efficacy of public service delivery systems.

\section{Conclusions}

The knowledge and network society (Castells, 2000a, 2000b) is stimulating a continuous and growing interest in promoting both knowledge sharing and knowledge-transfer flow, at the same time emphasising the critical role of transparency, especially in the public sector domain. Several studies have earned attention on these issues, even if, according to Kapucu (2014), more empirical studies are required.

This study contributes to this debate by illustrating a KMN meta-model and its implementation within a network of Italian LGs.

The model makes it possible for any interested parties to have open access to a common knowledge repository, facilitating the reuse of information. It is expected to increase transparency and improve the quality of services currently provided to citizens and create new integrated services, at the same time boosting the strategic view beyond the local territorial range.

Therefore, implementing a KMN would mean that the communities served by the LGs involved in the network can no longer be considered as an external component. However, findings from our study show how difficult going beyond such a restrictive view could be: achieving the advantages from the KMN model can be easy at the intra-organisational level, but it is harder at the network level (Dawes, 2013). On one hand, providing open access to data means creating a new situation where citizens (and other stakeholders) can use and reuse information through the network (Chun et al., 2010); on the other hand, there is the risk that citizens will still be considered outside the organisational boundaries. According to the institutional theory perspective, the introduction of IT sometimes does not change institutions, but rather fortifies both work practices in use and current organisational structures, despite the innovations the KMN can support (Janssen et al., 2012).

Bearing in mind the aim of this study, it can be observed that implementing a KMN is a complex task, since several steps are required to overcome technical and organisational barriers progressively. However, the high degree of flexibility of the model proposed in the previous sections is going to support this goal. As a matter of fact, the illustrated implementation 'validates' the general framework proposed in this study, which could also be taken as a reference in other contexts when the creation of a KMN is perceived as necessary. Indeed, the research team had the opportunity to validate the framework in a network of municipalities belonging to the "Ufita mountain community' (http://www.cmufita.it/cms/), where similar behavioural patterns have been observed, even though they have different goals. Moreover, the research team is investigating the implementation of such a model in the educational context (University), as well as in the private sector domain.

Future developments of the study will be based on the investigation of both the single node and the network as a whole for a more extended period, in order to unveil how the implementation of a KMN would affect future strategies of each LG, improving the effectiveness of services provided to citizens. 


\section{References}

Alvesson, M., \& Deetz, S. (2000). Doing Critical Management Research. London: Sage.

Amayah, A. T. (2013). Determinants of knowledge sharing in a public sector organization, Journal of Knowledge Management, 17(3), 454-471. https://doi.org/10.1108/JKM-11-2012-0369

Andreula, N., Chong, A., \& Guillén, J. (2009). Institutional quality and fiscal transparency. Inter-American Development Bank Working Paper 36.

Bartocci, L. (2008). Cultura manageriale e ICT nel percorso di rinnovamento. In AA.VV. Innovazione e accountability nella pubblica amministrazione. I drivers del cambiamento, RIREA, Roma: 372-386.

Bellver, A., \& Kaufmann, D. (2005). Transparenting transparency: initial empirics and policy applications.

Bertot, J. C., Jaeger, P. T., \& Grimes, J. M. (2010). Using ICTs to create a culture of transparency: E-government and social media as openness and anti-corruption tools for societies. Government Information Quarterly, 27(3), 264-271. https://doi.org/10.1016/j.giq.2010.03.001

Bisogno, M., Nota, G., \& Ianulardo, M. (2016). Transparency, accountability and fighting corruption. A model on whistle-blowing processes. In Beatriz Cuadrado-Ballesteros, Isabel Maria García-Sánchez (Eds.), Local Governments in the Digital Era: Looking for Accountability (pp. 171-185).

Bolisani, E., Scarso, E., \& Di Biagi, M. (2006). Economic Issues of Professional Communities. Encyclopedia of communities of Practice in Information and knowledge Management, Idea Group Reference.

Burns, J., \& Scapens, R.W. (2000). Conceptualizing management accounting change: An institutional framework, Management Accounting Research, 11, 3-25. https://doi.org/10.1006/mare.1999.0119

Cardoso, L., Meireles, A., \& Peralta, C.F. (2012). Knowledge management and its critical factors in social economy organizations, Journal of Knowledge Management, 16(2), 267-284. https://doi.org/10.1108/13673271211218861

Castells, M. (2000a). The information age: Economy, society and culture. The rise of the network society (Vol. 1, 2nd ed.). Oxford: Blackwell.

Castells, M. (2000b). The information age: Economy, society and culture. End of millennium (Vol. 3, 2nd ed.). Oxford: Blackwell.

Cegarra-Navarro, J. G., Soto-Acosta, P., \& Wensley, A. K. P. (2016). Structured knowledge processes and firm performance: The role of organizational agility, Journal of Business Research, 69, 1544-1549. https://doi.org/10.1016/j.jbusres.2015.10.014

Chun, S. A., Shulman, S., Sandoval, R., \& Hovy, E. (2010). Government 2.0: Making connections between citizens, data and government. Information Polity, 15(1/2), 1-9. https://doi.org/10.3233/IP-2010-0205

Cuadrado-Ballesteros, B., Mordán, N., \& Frías-Aceituno, J. V. (2016). Transparency as a Determinant of Local Financial Condition. In da Conceição Santos Ferreira, A., do Carmo Azevedo, G.M., da Silva Oliveira, J. \& Figueiredo Marques R. P. (Eds.), Global Perspectives on Risk Management and Accounting in the Public Sector. IGI Global.

Dawes, S. S. (2013). Public Sector Knowledge Networks: Measures and Conditions of Success. In Gil-Garcia, J. Ramon (Ed.), E-Government Success Factors and Measures. IGI Global

Dawes, S. S., Cresswell, A. M., \& Pardo, T. A. (2009). From need to know to need to share: tangled problems, information boundaries, and the building of public sector knowledge networks. Public Administration Review, 69(3), 392-402. https://doi.org/10.1111/j.1540-6210.2009.01987_2.x

De Angelis, C. T. (2013). Models of governance and the importance of KM for public administration, Journal of Knowledge Management Practice, 14(2), 1-18.

Del Sordo, C., Orelli, R. L., \& Padovani, E. (2015). Governing the Public Sector E-Performance: The Accounting Practices in the Digital Age, International Journal of Public Administration in the Digital Age, 2(4), 65-75. https://doi.org/10.4018/ijpada.2015100105

Demartini, P., \& Paoloni, P. (2013). Implementing an intellectual capital framework in practice, Journal of Intellectual Capital, 14(1), 69-83. https://doi.org/10.1108/14691931311289020

Di Maggio, P. J., \& Powell, W. W. (1983). The iron cage revised: Institutional isomorphism and collective rationality in organizational fields. American Sociological Review, 48, 147-160. 
https://doi.org/10.2307/2095101

Dong, T. P., Hung, C. L., \& Cheng, N. C. (2016). Enhancing knowledge sharing intention through the satisfactory context of continual service of knowledge management systems. Information Technology \& People, 29(4), 807-829. https://doi.org/10.1108/ITP-09-2014-0195

Ducci, G. (2015). Public Communication in the Processes of Transparency and Accountability in the Era of Open Data, Sociology Study, 5(2), 83-90. https://doi.org/10.17265/2159-5526/2015.02.001

Dumay, J. (2009). Intellectual capital measurement: a critical approach, Journal of Intellectual Capital, 10(2): 190-210. https://doi.org/10.1108/14691930910952614

Dumay, J. (2010). A critical reflective discourse of an interventionist research project. Qualitative Research in Accounting \& Management, 7(1), 46-70. https://doi.org/10.1108/11766091011034271

Edge, K. (2005). Powerful public sector knowledge management: a school district example. Journal of Knowledge Management, 9(6), 42-52. https://doi.org/10.1108/13673270510629954

European Union Commission (2015). Creating value through Open data. Retrieved from https://www.europeandataportal.eu/sites/default/files/edp_creating_value_through_open_data_0.pdf

Florini, A. (2000). Does the invisible hand need a transparent glove? Proceedings of the 11th Annual World Bank Conference on Development Economics. The World Bank, Washington, DC. Retrieved from $\mathrm{http}$ ://siteresources.worldbank.org/INTWBIGOVANTCOR/Resources/florini.pdf

Franco, G., Maresca, P., \& Nota, G. (2008). Identity, Negotiation and Trust in a Distributed Knowledge Management Network. In DMS 2008: Proceedings of the International Conference on Distributed Multimedia Systems Hyatt Harborside at Logan Intel Airport, Boston, USA: 336-342

Franco, G., Maresca, P., Nota, G., (2010). Modeling Social Influences in a Knowledge Management Network. International Journal of Distance Education Technologies, 8(1), 1-16. https://doi.org/10.4018/jdet.2010010101

Guillamón-López, M. D., Bastida, F., \& Benito, B. (2011). The determinants of Local Government's financial transparency, Local Government Studies, 37(4), 391-406. https://doi.org/10.1080/03003930.2011.588704

Hausenblas, M. (2009). Exploiting linked data to build web applications. IEEE Internet Computing, 13(4), 68-73. https://doi.org/10.1109/MIC.2009.79

HM Government. (2012). Open Data White Paper. Unleashing the potential. Retrieved from https://www.gov.uk/government/uploads/system/uploads/attachment_data/file/78946/CM8353_acc.pdf

Hollyer, J., Rosendorff, B. P., \& Vreeland, J. R. (2011). Democracy and transparency. The Journal of Politics, 73(4), 1191-1205. https://doi.org/10.1017/S0022381611000880

Jain, A. K., \& Jeppesen, H. J. (2013). Knowledge management practices in a public sector organisation: the role of leaders' cognitive styles. Journal of Knowledge Management, 17(3), 347-362. https://doi.org/10.1108/JKM-11-2012-0358

Janssen, M., Charalabidis, Y., \& Zuiderwijk, A. (2012). Benefits, Adoption Barriers and Myths of Open Data and Open Government, Information Systems Management, 2(4), 258-268. https://doi.org/10.1080/10580530.2012.716740

Jönsson, S., \& Lukka, K. (2006). Doing Interventionist Research in Management Accounting. Gothenburg Research Institute, Gothenburg.

Kapucu, N. (2014). Complexity, Governance, and Networks: Perspectives from Public Administration. Complexity, Governance \& Networks, 29-38. http://dx.doi.org/10.7564/14-CGN3

Kassen, M. (2017). Open data in Kazakhstan: incentives, implementation and challenges, Information Technology \& People, 30(2), 301-323. https://doi.org/10.1108/ITP-10-2015-0243

Kopits, G., \& Craig, J. (1998). Transparency in Government Operations, IMF Occasional Paper, vol. 158. International Monetary Fund, Washington.

Lipuntsov, Y. (2014). Three Types of Data Exchange in the Open Government Information Projects. In Proceedings of the 2014 Conference on Electronic Governance and Open Society: Challenges in Eurasia: 88-94.

Margetts, H. (2006). E-government in Britain-A decade on, Parliamentary Affairs, 59, 250-265. 
https://doi.org/10.1093/pa/gs1003

Martelo-Landroguez, S. \& Cegarra-Navarro, J.G. (2014). Linking knowledge corridors to customer value through knowledge processes. Journal of Knowledge Management, 18(2), 342-365. https://doi.org/10.1108/JKM-07-2013-0284

Massaro, M., Dumay, J., \& Garlatti, A. (2015). Public sector knowledge management: a structured literature review, Journal of Knowledge Management, 19(3), 530-558. https://doi.org/10.1108/JKM-11-2014-0466

Mcadam, R., \& Reid, R. (2000). A comparison of public and private sector perceptions and use of knowledge management, Journal of European Industrial Training, 24(6), 317-329. https://doi.org/10.1108/03090590010346424

McDermott, P. (2010). Building open government. Government Information Quarterly, 27(4), 401-413. https://doi.org/10.1016/j.giq.2010.07.002

Mercado-Lara, E., \& Gil-Garcia, J. (2014). Open government and data intermediaries. Proceedings of the $15^{\text {th }}$ Annual International Conference on Digital Government Research, 335-336.

Mussari, R. (2003). Il Knowledge Management System e l'innovazione manageriale nelle amministrazioni pubbliche italiane: l'esperienza di Cantieri, in AA.VV. Knowledge Management E Successo Aziendale, 26, 597-626.

Napoli, P. M., \& Karaganis, J. (2010). On making public policy with publicly available data: The case of U.S. communications policymaking. Government Information Quarterly, 27(4), 384-391. https://doi.org/10.1016/j.giq.2010.06.005

Nelson, R. R., \& Winter, S. G. (1982). An evolutionary theory of economic change. Cambridge, MA: Harvard Business Press.

Open Knowledge Foundation. (2012). Open Data Handbook Documentation. Retrieved from http://opendatahandbook.org/guide/en/

Organization for Economic Cooperation and Development (OECD). (2002). Foreign Direct Investment for Development-Maximising Benefits, Minimising Costs, OECD Secretariat. Retrieved from https://www.oecd.org/investment/investmentfordevelopment/1959815.pdf

Osborne, S. (2009). Delivering public services: Are we asking the right questions? Public Money \& Management, 29(1), 5-7. https://doi.org/10.1080/09540960802617269

Osborne, S. P., Radnor, Z., \& Nasi, G. (2012). A New Theory for Public Service Management? Toward a (Public) Service-Dominant Approach American Review of Public Administration, 43(2), 135-158. https://doi.org/10.1177/0275074012466935

Osborne, S. P., Radnor, Z., Vidal, I., \& Kinder, T. (2014). A sustainable business model for public service organizations? Public Management Review, 16(2), 165-172. https://doi.org/10.1556/SocEc.36.2014.3.1

Palacios-Marqués, D., Soto-Acosta, P., \& Merigó, J. M. (2015). Analyzing the effects of technological, organizational and competition factors on Web knowledge exchange in SMEs. Telematics and Informatics, 32(1), 23-32. https://doi.org/10.1016/j.tele.2014.08.003

Parker, L. (2004). Qualitative research. In Burton, S. \& Steane, P. (Eds), Surviving your Thesis (pp. 159-177). London: Routledge.

Rathi, D., Given, L. M., \& Forcier, E. (2014). Interorganisational partnerships and knowledge sharing: the perspective of non-profit organisations (NPOs). Journal of Knowledge Management, 18(5), 867-985. https://doi.org/10.1108/JKM-06-2014-0256

Reason, P., \& Bradbury, H. (2006). Handbook of Action Research: The Concise Paperback Edition. London: Sage.

Ryan, B., Scapens, R. W., \& Theobold, M. (2002). Research Method and Methodology in Finance and Accounting (2nd ed.). London: Thomson.

Scapens, R. W., \& Varoutsa, E. (2010). Accounting in Inter-Organisational Relationships - The Institutional Theory Perspective. In H. Håkansson, K. Kraus \& J. Lind (Eds.), Accounting in networks (pp. 314-341). New York: Routledge.

Scott, R. W. (1992). Organizations: Rational, natural and open systems (3rd ed.). Englewood Cliffs, New York, Prentice Hall. 
Scott, R. W., \& Meyer, J. W. (1992). The organization of societal sectors. In Meyer, J.W. \& Scott, R.W. (Eds.), Organizational environments: Ritual and rationality, (pp. 129-144). Updated edition, Beverly Hills, CA, Sage Publications.

Soto-Acosta, P., \& Cegarra-Navarro, J. G. (2016). New ICTs for Knowledge Management in Organizations. Journal of Knowledge Management, 20(3), 417-422. https://doi.org/10.1108/JKM-02-2016-0057

Stankosky, M. (2005). Advances in knowledge management: university research toward an academic discipline. In Creating the discipline of knowledge management: the latest in university research. Elsevier Butterworth-Heinemann, Amsterdam.

Steccolini, I. (2004). Is the Annual Report an Accountability Medium? An Empirical Investigation into Italian Local Governments. Financial Accountability \& Management, 20(3), 327-350. https://doi.org/10.1111/j.0267-4424.2004.00389.x

Tat-Kei Ho, A. (2002). Reinventing local governments and the e-government initiative. Public Administration Review, 62, 434-444. https://doi.org/10.1111/0033-3352.00197

Uzzi, B., \& Lancaster, R. (2003). Relational embeddedness and learning: the case of bank loan managers and their clients. Management Science, 49(4), 383-399. https://doi.org/10.1287/mnsc.49.4.383.14427

Vătămănescu, E. M., Andrei A. G., Dumitriu, D. L., \& Leovaridis, C. (2016). Harnessing network-based intellectual capital in online academic networks. From the organizational policies and practices towards competitiveness, Journal of Knowledge Management, 20(3), 594-619. https://doi.org/10.1108/JKM-05-2015-0208

Vishwanath, T., \& Kaufmann, D., (2001). Toward Transparency: New Approaches and Their Application to Financial Markets. The World Bank Research Observer, 16(1) (Spring 2001), 41-57.

Williams, A. (2015). A global index of information transparency and accountability. Journal of Comparative Economics, 43, 804-824. https://doi.org/10.1016/j.jce.2014.10.004

\section{Notes}

Note 1 . The openness degree can be classified by the 'five stars' model presented by Tim Berners Lee in 2010 that starts from any data available on the Web in whatever format and with open licence, like unstructured files (one star) up to Linked Open Data (five stars) (http://5stardata.info/en/).

Note 2. For reference see http://www.progettokalimera.it.

\section{Copyrights}

Copyright for this article is retained by the author(s), with first publication rights granted to the journal.

This is an open-access article distributed under the terms and conditions of the Creative Commons Attribution license (http://creativecommons.org/licenses/by/4.0/). 